\title{
Fenestration and dehiscence frequency in maxillary teeth with apical periodontitis: a CBCT study
}

\author{
Frecuencia de dehiscencias y fenestraciones en dientes maxilares con \\ periodontitis apical: un estudio con TCHC
}

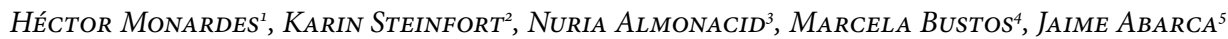

\begin{abstract}
Endodontics Specialization Program, Facultad de Odontología, Universidad San Sebastián, Santiago, Chile (DD) 0000-0001-7964-5618 Endodontics Specialization Program, Facultad de Odontología, Universidad San Sebastián, Santiago, Chile. (10) 0000-0003-1980-7093 Endodontics Specialization Program, Facultad de Odontología, Universidad San Sebastián, Santiago, Chile. (10) 0000-0002-6623-7970 Endodontics Specialization Program, Facultad de Odontología, Universidad San Sebastián, Santiago, Chile. (10) 0000-0002-9490-0848 Faculty of Dentistry, Facultad de Odontología, Universidad San Sebastián, Santiago, Chile. (D) 0000-0002-1068-6814
\end{abstract}

\section{Abstract}

Introduction: to determine the frequency of fenestration and dehiscence bone defects present in maxillary teeth with apical periodontitis, mainly in teeth with endodontic treatment, as they are frequently cause of nonspecific symptoms after treatment. Methods: 1201 Maxillary Cone Beam Computed Tomography

Keywords: cone beam computed tomography, fenestration, dehiscence, maxillary teeth, endodontically treated teeth (CBCT) exams were analyzed and 803 teeth with apical periodontitis were selected. Results: of the teeth with apical periodontitis, 142 had a fenestration defect (18\%) of which 105 teeth $(74 \%)$ were endodontically treated. The highest frequency was observed in premolars, with no statistical differences between groups. Dehiscence defect was found in 139 teeth (17\%) out of which 90 (65\%) were endodontically treated. The highest frequency was observed in molars, with statistical differences in relation to other tooth types $(p<0.001)$. Conclusion: an important number of teeth with apical periodontitis present dehiscence or fenestration bone defects, especially in teeth with root canal treatment.

\section{Resumen}

Introducción: determinar la frecuencia de fenestraciones y dehiscencias presentes en dientes maxilares con periodontitis apical, principalmente en dientes con tratamiento de endodoncia, pues frecuentemente

Palabras clave: tomografía computarizada de haz cónico, fenestración, dehiscencia, diente maxilar, diente endodónticamente tratado son causa de síntomas inespecíficos después del tratamiento. Métodos: se examinaron y analizaron 1201 tomografías computarizadas de haz cónico (TCHC), y se seleccionaron 803 dientes con periodontitis apical. Resultados: de los dientes con periodontitis apical, 142 presentaban fenestración (18\%), de los cuales, 105 dientes (74\%) estaban tratados endodónticamente. La mayor frecuencia fue observada en premolares, sin diferencias estadísticas entre los grupos. La dehiscencia fue encontrada en 139 dientes (17\%), de los cuales 90 (65\%) estaban tratados endodónticamente. La mayor frecuencia fue encontrada en molares con diferencia estadísticas en relación con los otros tipos de dientes $(p<0,001)$. Conclusión: un importante número de dientes con periodontitis apical presentan fenestraciones y dehiscencias, especialmente en dientes con tratamiento de canales radiculares.

Submitted: August 11/2020 - Accepted: November 03/2020

How to quote this article: Monardes $\mathrm{H}$, Steinfort $\mathrm{K}$, Almonacid N, Bustos $\mathrm{M}$, Abarca J. Fenestration and dehiscence frequency in maxillary teeth with apical periodontitis: a CBCT study. Rev Fac Odontol Univ Antioq. 2021; 33(1): 36-44. DOI: http://dx.doi.org/10.17533/udea.rfo.v33n1a3

\section{INTRODUCTION}

Apical periodontitis may occur as an evolution of pulpal disease of bacterial etiology, generating pathological changes in apical tissues such as alveolar bone loss. When it is left untreated, this bone loss can extend to important anatomical structures such as the maxillary sinus, nasal floor or sublingual space; it may also extend to the cortical surface of the alveolar bone ${ }^{1}$. Two phenomena that have been scarcely studied in endodontics, and that could be associated with apical periodontitis, are fenestration and dehiscence bone defects, which are anatomical 
variations relative to bone morphology. A fenestration is an isolated area in which the root of a tooth has bone resorption and it is only covered by periosteum and gingival tissues, but maintains an intact marginal ridge. But when the bone resorption involves the marginal ridge, it is called a dehiscence ${ }^{2}$. Etiological factors such as age-related anatomical changes, prominent roots, thin alveolar bone, crowding, misalignment and/or tooth function, have been proposed ${ }^{3,4}$. The presence of apical or periodontal pathosis could also explain the presence of these types of defects ${ }^{2,5,6}$. Fenestration defects are difficult to assess clinically and in endodontically treated teeth may be confused with symptomatic periodontitis or other types of orofacial pain, as they can present tenderness to sustained apical pressure and discomfort. This could lead to misdiagnosis and overtreatment of teeth with this type of bone defect ${ }^{7,8}$.

Diagnosis of bone defects through two-dimensional imaging has its limitations, such as overlapping of anatomical structures, underestimation of the presence and size of bone defects and projection or observational errors ${ }^{9}$. There is research that shows that funnelshaped or lingual bone defects cannot be detected and that buccal loss of structure can be misdiagnosed ${ }^{9}$. Three-dimensional imaging, such as Cone Beam Computed Tomography (CBCT) offers useful information and its application in clinical practice has several advantages over conventional tomography, such as lower exposure doses, shorter acquisition time and higher resolution ${ }^{10}$. A study that compared 2D and 3D imaging of artificial bone defects demonstrated that CBCT had $100 \%$ sensitivity for the detection and classification of artificial bone defects, while intraoral $X$ rays had $67 \%$ sensitivity ${ }^{9}$. Moreover, CBCT has shown an absence of image distortion and structure overlapping ${ }^{5}$.

Apical periodontitis is of the outmost importance in endodontics and its association with fenestration and dehiscence bone defects is, to the knowledge of the authors, unknown. The aim of this study was to assess the frequency of teeth with apical periodontitis and their association to fenestration and dehiscence bone defects, through the use of CBCT, to take into account this anatomical condition in teeth that present nonspecific symptoms after endodontic treatment, which induce a misdiagnosis and a bad suggest repetition of root canal treatment.

\section{METHODS}

A cross-sectional study was conducted, previous approval by the ethics committee of the university San Sebastian, resolution 2019-50. The sample consisted of 1201 CBCT images, taken as part of the diagnosis or planning of dental treatments between November 2014 and June 2016 in the Begmax Radiological Center in Santiago de Chile. The CBCT exams that were included presented maxillary teeth with apical periodontitis with or without endodontic treatment of patients between 15 and 91 years of age. Third Molars and teeth without coronal structure or with the presence of metallic posts or crowns were excluded from analysis.

The CBCT images were obtained by qualified personnel using a Gendex ${ }^{\circledR}$ CB 500 I-CAT that operates with $120 \mathrm{KVp}$ and $5 \mathrm{~mA}$, with pulsed exposure and an effective dose of 36 to $74 \mu \mathrm{Sv}$. Voxel size was $0.2 \mathrm{~mm}$ and slice thickness was $0.2 \mathrm{~mm}$. Prior to the image analysis, two 
observers were subjected to a theoretical and practical calibration process, in which each evaluator analyzed ten CBCT images independently under the same conditions of time, light and screen resolution. Ten days later the procedure was repeated under the same conditions. With the results obtained, the interobserver agreement was calculated using Cohen's Kappa coefficient, obtaining an agreement of 1 for fenestrations and 0.9 for dehiscence.

Image observation was performed using the I-CAT Vision in a 32 inches screen with 1080p resolution. Each plane was zoomed to $150-200 \%$ to obtain a better visualization of the defects. Anterior teeth were evaluated in the sagittal plane (Figure 1) and posterior teeth in the coronal plane (Figure 2), and after this, all roots were identified and evaluated throughout its entire length.

The results were collected and registering gender, age, tooth type, presence or absence of endodontic treatment and presence or absence of fenestration and dehiscence bone defects. A descriptive statistical analysis was conducted to obtain central tendency measures using Systat v.13.0 program (STATA Corp. Texas, USA). Chi Squared Test and Fisher's Exact Test were used for the association of defect type and tooth type.

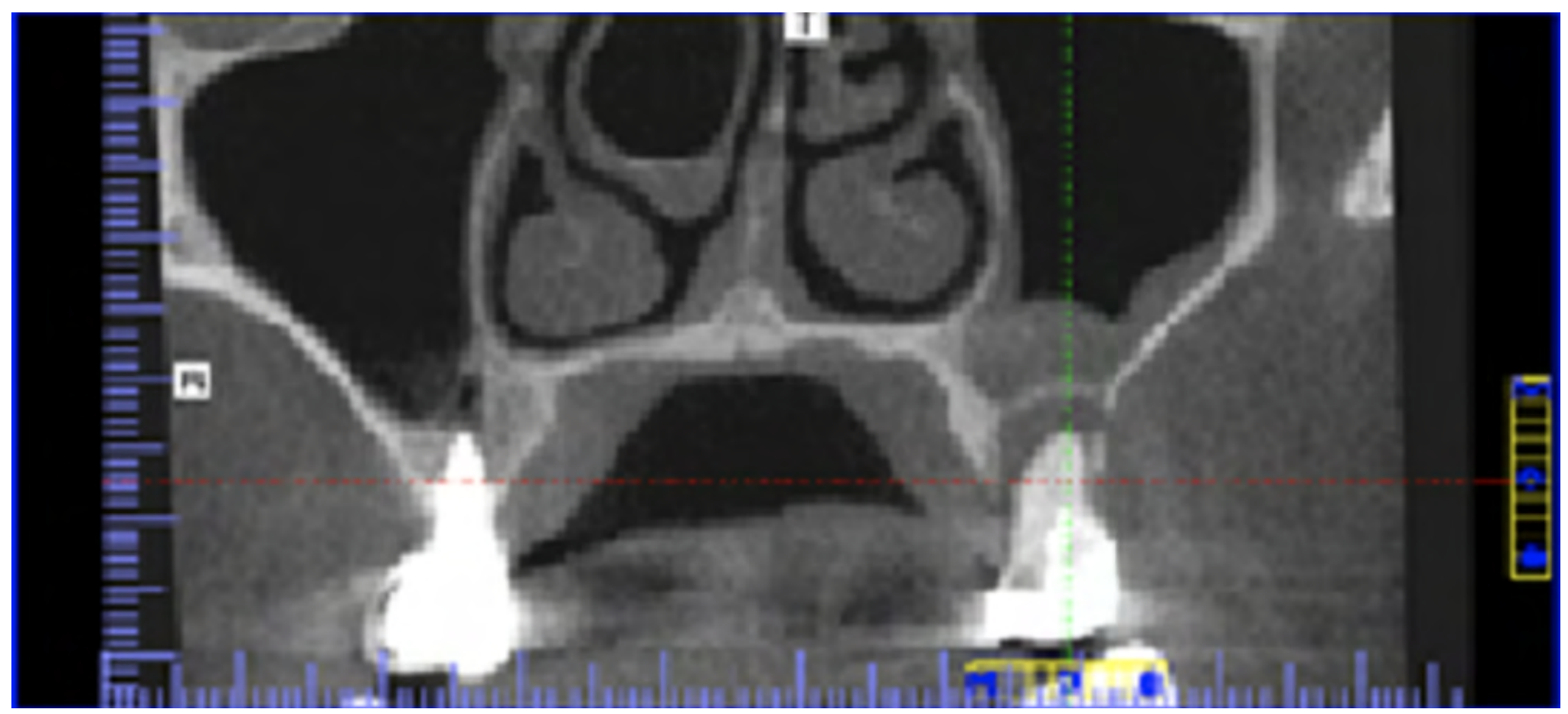

Figure 1. Female patient, 50 years of age, presents a fenestration in the mesiobuccal root of tooth 26 Source: by authors 


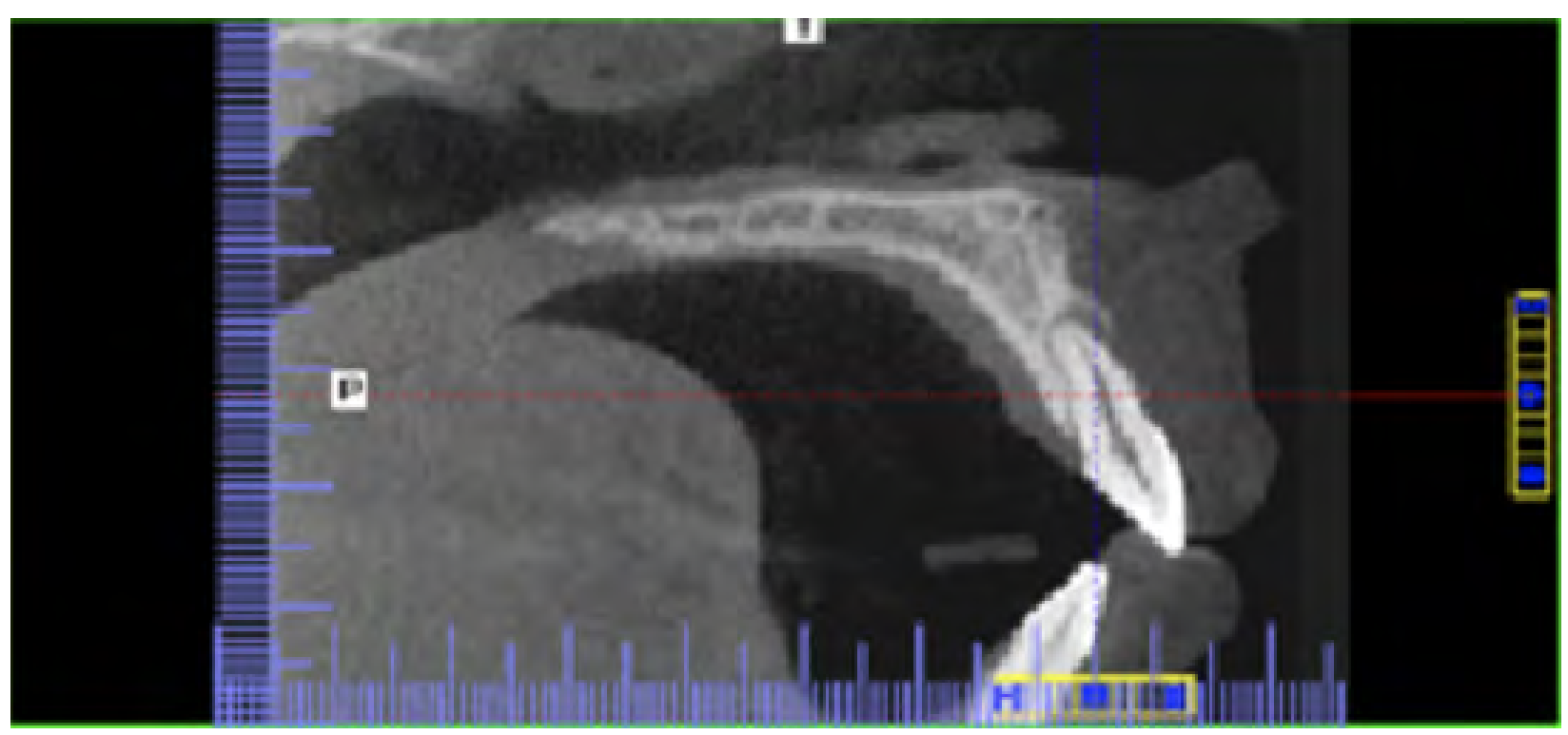

Figure 2. Female patient, 35 years of age, presents a dehiscence in tooth 21

Source: by authors

\section{RESULTS}

Of the 1201 CBCT exams evaluated, 510 met the inclusion criteria of which 286 corresponded to women. The average age was 41 years (SD 11.44y). The obtained sample consisted of 803 teeth: 281 anterior teeth, 261 premolars and 261 molars. Table 1 shows the number of teeth that presented bone defects and the frequency in which they presented endodontic treatment.

Table 1. Frequency of bone defects in teeth with apical periodontitis with or without the presence of root canal treatment

\begin{tabular}{cccccc}
\hline & TWAP & FE & \%FE & DE & \%DE \\
\hline Without RCT & 223 & 37 & 17 & 49 & 22 \\
With RCT & 580 & 105 & 18 & 90 & 16 \\
Total & 803 & 142 & 18 & 139 & 17 \\
\hline
\end{tabular}

TWAP, Tooth with apical periodontitis; FE, Fenestration; DE, Dehiscence; Without RCT, root canal treatment; with RCT, root canal treatment Source: by authors

Fenestrations were more frequently found in first premolars (39\% for tooth 14 and $30 \%$ for 24 ) with no statistical differences between groups, and the larger frequency of dehiscence was found in molars (21\%) (Table 2), which was statistically significant according to Chi-Squared Test and Fisher's Exact Test with a 95\% confidence $(p<0.001)$. Teeth with one root and buccal roots in multi rooted teeth presented the highest frequency of bone defects (Table 3). 
Table 2. Tooth type and frequency of bone defects with or without the presence of root canal treatment

\begin{tabular}{cccccccc}
\hline TT & NTBD & FE & FERCT & FEWRCT & DE & DERCT & DEWRCT \\
\hline A & 281 & $53 / 19 \%$ & $34 / 64 \%$ & $19 / 36 \%$ & $54 / 19 \%$ & $35 / 65 \%$ & $19 / 35 \%$ \\
PM & 261 & $57 / 22 \%$ & $46 / 81 \%$ & $11 / 19 \%$ & $31 / 12 \%$ & $22 / 71 \%$ & $9 / 29 \%$ \\
M & 261 & $32 / 12 \%$ & $25 / 78 \%$ & $7 / 22 \%$ & $54 / 21 \%$ & $33 / 61 \%$ & $21 / 39 \%$ \\
Total & 803 & $142 / 18 \%$ & $105 / 74 \%$ & $37 / 26 \%$ & $139 / 17 \%$ & $90 / 65 \%$ & $49 / 35 \%$ \\
\hline
\end{tabular}

$\Pi$, Tooth type; A, Anterior; PM, Premolar; M, Molar; NTBD, number of teeth with bone defects; FE, fenestration; FERCT, Fenestration and root canal treatment; FEWRCT, Fenestration without root canal treatment; DE, Dehiscence; DERCT, Dehiscence and root canal treatment; DEWRCT, Dehiscence without root canal treatment

Source: by authors

Table 3. Bone defect by root with or without root canal treatment

\begin{tabular}{crrrrrr}
\hline Root & FE & FERCT & FEWRCT & DE & DERCT & DEWRCT \\
\hline DB & 23 & 15 & 8 & 27 & 18 & 9 \\
MB & 29 & 24 & 5 & 44 & 30 & 14 \\
P & 7 & 5 & 2 & 32 & 12 & 20 \\
U & 73 & 51 & 22 & 73 & 50 & 23 \\
B & 37 & 29 & 8 & 12 & 7 & 5 \\
Total & 169 & 124 & 45 & 188 & 117 & 71 \\
\hline
\end{tabular}

DB, Distobuccal; MB, Mesiobuccal; P, Palatal; U, One rooted tooth; B, Buccal; FE, fenestration; FERCT, Fenestration and root canal treatment; FEWRCT, Fenestration without root canal treatment; DE, Dehiscence; DERCT, Dehiscence and root canal treatment; DEWRCT, Dehiscence without root canal treatment

Source: by authors

In relation to the presence of bone defects and gender, the highest frequency was found amongst women. In association with age, the highest frequency for fenestration was found in women between the ages of 51 and 60 and men between the ages of 61 and 70 (Figure 1); for dehiscence was between the ages of 41 and 60, for both men and women (Figure 2).

\section{DISCUSSION}

CBCT is one of the best imaging tools available for evaluating bone servings as periodontal support in specific areas of interest. A limitation common to all studies that use CBCT for measurements is the thin spatial resolution. Delicate structures as the alveolar buccal bone are especially susceptible to the partial volume effect. The larger the FOV, the lower the resolution of the image, this can make it very difficult to detect thin bone $(<1 \mathrm{~mm})^{11}$.

Peterson asserts than $\mathrm{CBCT}$ imaging overestimate the presence of dehiscence and fenestration defects $^{12}$ but, Timock found strong agreement between CBCT and direct measurements for buccal bone height and thickness, which speaks for the accuracy and reliability of CBCT in measuring these parameters ${ }^{13}$. 
Also, Sun showed that under $0.125 \mathrm{~mm}$ voxel size, both sensitivity and specificity for dehiscence and fenestration were acceptable ${ }^{14}$, and showed a higher reliability of measuring the vertical diameter of dehiscences and fenestration by $\mathrm{CBCT}^{15}$.

The presence of fenestration and dehiscence bone defects was observed in teeth with apical periodontitis that may or may not have been endodontically treated. According to the results, 803 teeth with apical periodontitis were found in 510 CBCT exams, out of which 281 had a bone defect. These findings show that more than a third of the teeth with apical periodontitis presented these types of defects ( $18 \%$ for fenestration and $17 \%$ for dehiscence). These results are difficult to compare with other studies, since we only evaluated teeth with apical periodontitis; but when compared with other studies that evaluated bone defects, the percentages are higher than what was observed by Grimoud et al, for fenestration $10.5 \%{ }^{3}$, Rupprecht et al, $9 \%$ for fenestration and $4.1 \%$ for dehiscence ${ }^{6}$ and Nimigean et al, $12.8 \%$ for the sum of both defects ${ }^{2}$. Our results are generally higher than what was reported in several past studies (frequency ranging from $12-29 \%$ vs the $35 \%$ of teeth with defects observed in this study), which may be attributed to the fact that the observation was limited to teeth with apical periodontitis.

The teeth that most frequently presented fenestrations were premolars $(22 \%)$, which is consistent with what was observed in other studies ${ }^{4,16}$. In a study by Jang et el, it was observed that the buccal plate was thinner in maxillary premolars ${ }^{17}$, the same in Temple et al for the first premolar, so this higher frequency of bone defects in premolars could be of anatomical origin, however, there were no statistical differences between tooth types. ${ }^{18}$ The results found in this study do not agree with Rupprecht et al and Nimigean et al, who found that first molars had the highest frequency of fenestrations (37 and $42.6 \%$, respectively $)^{2,6}$ nor with Grimoud et al, who found that anterior teeth were the most affected. ${ }^{3}$ Ethnicity may play an important role in these differences, considering different bone structures and the presence of malocclusions ${ }^{19}$; although Grimoud et al, proposes that the presence of bone defects is transversal to populations and time periods ${ }^{3}$.

Regarding dehiscence defects, molars presented the highest frequency $(21 \%)(p<0.001)$, being tooth 26 the most affected (35\%), followed by anterior teeth (19\%; tooth $21,31 \%)$, which is in agreement with Rupprecht et $\mathrm{al}^{6}$. However, this does not agree with the results obtained by Nimigean et al, Yagci et al and Evangelista et al, in which the most affected maxillary teeth were canines ${ }^{2,4,19}$. Grimoud et al found similar results for canines and first molars ${ }^{3}$.

Regarding gender, more fenestration and dehiscence defects were found in women than in men (54.2\% and 50.4\%, respectively), which is similar to that reported by Rupprecht et al for African-american females ${ }^{6}$. More fenestrations were found in women ranging from 61 to 70 years of age and more dehiscence defects in men and women ranging 41 to 50 years of age. This difference may be attributed to the fact that these age groups were the most common amongst the sample involved in this study. In a study by Jang et al, it was observed that the distance from apex to buccal surface was smaller in women than in men and that this distance appeared to decrease with age ${ }^{17}$. This could help explain why more bone defects were observed in women and aging patients. On the other hand, Nimigean 
et al, found a rather constant frequency of defects in different age groups and even a slight decrease of fenestrations with age ${ }^{2}$. Pan et al, also observed a decrease in fenestrations with age, which they inferred could be attributed to tooth loss ${ }^{16}$. Temple et al and Pan et al found no significant associations between defects and gender ${ }^{16,18}$.

Buccal surfaces were the most frequently affected, which is consistent to what was observed in several studies ${ }^{3,5,16,19}$. Buccal bone plate is thinner and less dense than the palatal bone plate; also, buccal roots tend to be more divergent than palatal roots, which could also favor a thinner bone layer. Because of this, apical periodontitis in one of these roots would be more likely to produce a fenestration or dehiscence defect, than a palatal root periodontitis ${ }^{5}$.

In relation to endodontic treatment, it was found that $74 \%$ of fenestration and $65 \%$ of dehiscence defects were present in endodontically treated teeth, one rooted-teeth being the most affected. This study lacks data of the teeth prior to the endodontic treatment, which prevents us from making assumptions of treatment success or failure. This high prevalence of bone defects in endodontically treated teeth with apical pathosis, could be because they are repairing, are suffering of delayed repair or the treatment failed to create an environment conducive to bone repair. In a study conducted by Yoshioka et al, they analyzed CBCT exams of patients with persistent apical lesions in endodontically treated teeth. The most common bone lesion observed in maxillary teeth was buccal fenestration $(69 \%)^{5}$. Further studies are required to shed a light in the role of fenestration or dehiscence in the prognosis of these types of cases $^{16}$.

\section{CONCLUSIONS}

There is an important number of teeth with apical periodontitis that present fenestration $(18 \%)$ and dehiscence $(17 \%)$ bone defects, being one rooted-teeth and buccal roots the most affected by them. In $74 \%$ of fenestration defects and $60 \%$ of dehiscence defects, the teeth were endodontically treated.

\section{CONFLICTS OF INTEREST}

The authors declare that there is no conflict of interest.

\section{CORRESPONDING AUTHOR}

Héctor Monardes

hector.monardes@uss.cl

Bellavista 7, Recoleta

(+56) 992184530

Santiago, Chile 


\section{REFERENCES}

1. Cotti E, Vargiu P, Dettori C, Mallarini G. Computerized tomography in the management and followup of extensive periapical lesion. Endod Dent Traumatol. 1999; 15(4): 186-9. DOI: https://doi. org/10.1111/j.1600-9657.1999.tb00799.x

2. Nimigean VR, Nimigean V, Bencze MA, Dimcevici-Poesina N, Cergan R, Moraru S. Alveolar bone dehiscences and fenestrations: an anatomical study and review. Rom J Morphol Embryol. 2009; 50(3): 391-7.

3. Grimoud AM, Gibbon VE, Ribot I. Predictive factors for alveolar fenestration and dehiscence. Homo. 2017; 68(3): 167-75. DOI: https://doi.org/10.1016/j.jchb.2017.03.005

4. Yagci A, Veli I, Uysal T, Ucar Fl, Ozer T, Enhos S. Dehiscence and fenestration in skeletal Class I, II, and III malocclusions assessed with cone-beam computed tomography. Angle Orthod. 2012; 82(1): 67-74. DOI: https://doi.org/10.2319/040811-250.1

5. Yoshioka T, Kikuchi I, Adorno CG, Suda H. Periapical bone defects of root filled teeth with persistent lesions evaluated by cone-beam computed tomography. Int Endod J. 2011; 44(3): 245-52. DOI: https:// doi.org/10.1111/j.1365-2591.2010.01814.x

6. Rupprecht RD, Horning GM, Nicoll BK, Cohen ME. Prevalence of dehiscences and fenestrations in modern American skulls. J Periodontol. 2001; 72(6): 722-9. DOI: https://doi.org/10.1902/jop.2001.72.6.722

7. Pasqualini D, Scotti N, Ambrogio P, Alovisi M, Berutti E. Atypical facial pain related to apical fenestration and overfilling. Int Endod J. 2012; 45(7): 670-7. DOI: https://doi.org/10.1111/j.1365-2591.2012.02021.x

8. Furusawa M, Hayakawa $\mathrm{H}$, Ida $\mathrm{A}$, Ichinohe T. A case of apical fenestration misdiagnosed as persistent apical periodontitis. Bull Tokyo Dent Coll. 2012; 53(1): 23-6. DOI: https://doi.org/10.2209/tdcpublication.53.23

9. Misch KA, Yi ES, Sarment DP. Accuracy of cone beam computed tomography for periodontal defect measurements. J Periodontol. 2006; 77(7): 1261-6. DOI: https://doi.org/10.1902/jop.2006.050367

10. Loubele M, Van Assche N, Carpentier K, Maes F, Jacobs R, van Steenberghe D et al. Comparative localized linear accuracy of small-field cone-beam CT and multislice CT for alveolar bone measurements. Oral Surg Oral Med Oral Pathol Oral Radiol Endod. 2008; 105(4): 512-8. DOI: https://doi.org/10.1016/j. tripleo.2007.05.004

11. Song Hee O, Kyung-Yen N, Seong-Hun K, Gerald N. Alveolar bone thickness and fenestration of incisors in untreated Korean patients with skeletal class III malocclusion: a retrospective 3-dimensional cone-beam computed tomography study. Imaging Sci Dentistry. 2020; 50(1): 9-14. DOI: https://doi.org/10.5624/ isd.2020.50.1.9

12. Peterson AG, Wang M, Gonzalez S, Covell Jr DA, Katancik J, Sehgal HS. An In Vivo and cone beam computed tomography investigation of the accuracy in measuring alveolar bone height and detecting dehiscence and fenestration defects. Int J Oral Maxillofac Implants. 2018; 33(6): 1296-1304. DOI: https:// doi.org/10.11607/jomi.6633

13. Timock AM, Cook V, McDonald T, Leo MC, Crowe J, Benninger BL et al. Accuracy and reliability of buccal bone height and thickness measurements from cone-beam computed tomography imaging. Am J Orthod Dentofacial Orthop. 2011; 140(5): 734-44. DOI: https://doi.org/10.1016/j.ajodo.2011.06.021

14. Sun L, Zhang L, Shen G, Wang B, Fang B. Accuracy of cone-beam computed tomography in detecting alveolar bone dehiscences and fenestrations. Am J Orthod Dentofacial Orthop. 2015; 147(3): 313-23. DOI: https://doi.org/10.1016/j.ajodo.2014.10.032 
15. Sun L, Yuan L, Wang B, Zhang L, Shen G, Fang B. Changes of alveolar bone dehiscence and fenestration after augmented corticotomy-assisted orthodontic treatment: a CBCT evaluation. Pro Orthod. 2019; 20(1): 1-7. DOI: https://doi.org/10.1186/s40510-019-0259-z

16. Pan HY, Yang $\mathrm{H}$, Zhang R, Yang YM, Wang H, Hu T et al. Use of cone-beam computed tomography to evaluate the prevalence of root fenestration in a Chinese subpopulation. Int Endod J. 2014; 47(1): 10-9. DOI: https://doi.org/10.1111/iej.12117

17. Jang JK, Kwak SW, Ha JH, Kim HC. Anatomical relationship of maxillary posterior teeth with the sinus floor and buccal cortex. J Oral Rehabil. 2017; 44(8): 617-25. DOI: https://doi.org/10.1111/joor.12525

18. Temple KE, Schoolfield J, Noujeim ME, Huynh-Ba G, Lasho DJ, Mealey BL. A cone beam computed tomography (CBCT) study of buccal plate thickness of the maxillary and mandibular posterior dentition. Clin Oral Implants Res. 2016; 27(9): 1072-8. DOI: https://doi.org/10.1111/clr.12688

19. Evangelista K, Vasconcelos KF, Bumann A, Hirsch E, Nitka M, Silva MA. Dehiscence and fenestration in patients with Class I and Class II Division 1 malocclusion assessed with cone-beam computed tomography. Am J Orthod Dentofacial Orthop. 2010; 138(2): 133.e1-7; discussion -5. DOI: https://doi.org/10.1016/j. ajodo.2010.02.021 